Volume 4 No. 3 Juli 2019

p-ISSN: 2477-8192 dan e-ISSN: 2502-2776

\title{
PEMETAAN PERSEBARAN HUTAN MENURUT KLASIFIKASI ARAHAN FUNGSI KAWASAN HUTAN DI KABUPATEN KONAWE SELATAN BERBASIS SIG
}

\author{
Anni Hardianti ${ }^{1}$, La Harudu ${ }^{2}$ \\ ${ }^{1}$ Program Studi Pendidikan Geografi \\ Universitas Halu Oleo \\ Email: annihardianti96@gmail.com \\ ${ }^{2}$ Program Studi Pendidikan Geografi \\ Universitas Halu Oleo \\ Email: annihardianti96@gmail.com
}

(Received: 3 Mei 2019 ; Reviewed: 10 Mei 2019; Accepted: 7 Juli; Published: 8 Juli 2019)

\begin{abstract}
The problems in this study are as follows: How is the direction of the function of protected forest, permanent production forest and limited production forest in south konawe district: Knowing the distribution of the direction of forest area functions in south konawe District. This study will be conduct in January 2019 with the location of South Konawe District, Southeast Sulawesi. This study uses an overlay method with scoring between existing parameters, where every parameter carried out a scoring process by giving the weight and value according to each classification that then overlay using ArcGIS 10.2 software. The use of this software utilizes the Geographic Information System (GIS) that can explain and present the functions of forest areas in digital form. From the results of data, analysis conclusions obtained as follows: (1) Distribution of forest area functions in South Konawe Regency consists of three namely forest areas protection, permanent production forest areas and limited production forest areas. The protected forest areas in Konawe Selatan District are located in several sub-districts like Wolasi, Moramo Utara, Moramo, Konda, Laeya, Kolono, Kolono Timur, Baito, Buke, Landono, Ranomeeto, Mowila, Palangga and Tinanggea, from the three forest areas production still has the most dominating area of $260505.86 \mathrm{ha}$, and protected forest area of 209495.28 ha, and limited production forest area $51363.48 \mathrm{ha}$.
\end{abstract}

Keywords: Mapping, Forest area distribution, Geographic Information System

\begin{abstract}
ABSTRAK
persebaran arahan fungsi kawasan hutan lindung, hutan produksi tetap dan hutan produksi terbatas di Kabupaten Konawe Selatan. Tujuan penelitian: Mengetahui sebaran arahan fungsi kawasan hutan di Kabupaten Konawe Selatan. Penelitian ini akan dilaksanakan pada bulan Januari 2019 dengan lokasi Kabupaten Konawe Selatan, Sulawesi Tenggara. Penelitian ini menggunakan metode overlay dengan scoring antara parameter-parameter yang ada, dimana setiap parameter dilakukan proses scoring dengan pemberian bobot dan nilai yang sesuai dengan pengklasifikasiannya masing-masing yang kemudian dilakukan overlay menggunakan software ArcGIS 10.2. Penggunaan software ini memanfaatkan Sistem Informasi Geografis (SIG) yang dapat menjelaskan dan mempresentasikan fungsi kawasan hutan dalam bentuk digital. Dari hasil analisis data diperoleh kesimpulan sebagai berikut: Persebaran fungsi kawasan hutan yang berada di Kabupaten Konawe Selatan terdiri atas tiga yaitu kawasan hutan lindung, kawasan hutan produksi tetap dan kawasan hutan produksi
\end{abstract}


terbatas. Kawasan hutan lindung di Kabupaten Konawe Selatan terletak di beberapa Kecamatan seperti Kecamatan Wolasi, Moramo Utara, Moramo, Konda, Laeya, Kolono, Kolono timur, Baito, Buke, Landono, Ranomeeto, Mowila, Palangga dan Tinanggea, dari ketiga kawasan hutan tersebut kawasan hutan produksi tetap mempunya luas yang paling mendominasi yaitu sebesar 260505,86 ha, dan kawasan hutan lindung sebesar 209495,28 ha, dan kawasan hutan produksi terbatas 51363,48 ha.

Kata Kunci: Pemetaan, Persebararan kawasan hutan, Sistem Informasi Geografis

\section{PENDAHULUAN}

Menurut Prahasta (2004) dalam Lestari, dkk (2016), SIG merupakan gabungan dari tiga unsur pokok: sistem, informasi, geografis. Sistem informasi geografis merupakan sistem informasi yang bebasis komputer, yang dirancang untuk bekerja dengan menggunakan data yang memiliki informasi spasial (bereferensi keruangan). Dengan menggunakan berbagai jenis data pada satu titik tertentu yang ada dibumi dapat digabungkan, dihubungkan, dianalisi, hingga memetakan hasilnya.

Pemetaan merupakan salah satu kegunaan sistem informasi geografis. Pemetaan merupakan pengelompokkan suatu kumpulan wilayah yang berkaitan dengan beberapa letak geografis wilayah meliputi dataran tinggi, pegunungan sumber daya dan potensi penduduk yang berpengaruh terhadap sosial kultural yang memiliki ciri khas khusus dalam penggunaan skala yang tepat.

Hutan Konawe Selatan merupakan hutan yang berpotensial menopang berbagai kebutuhan kehidupan masyarakat, akan tetapi kondisi hutan di Kabupaten Konawe Selatan saat ini mengalami kerusakan yang salah satunya diakibatkan oleh penjarahan atau penebangan secara liar, pemanfaatan sumber daya alam

hutan yang lebih memperoleh keuntungan ekonomi sehingga eksploitasi sumber daya alam hutan dan lingkungan kurang memperhatikan kaidah-kaidah konservasi.

Menurut BPS Kabupaten Konawe Selatan Tahun 2013, Kabupaten Konawe Selatan memiliki luas wilayah sebesar $451421 \mathrm{Km}^{2}$ yang sebagian besar wilayah tersebut berupa hutan yaitu seluas $287.847 \mathrm{Km}^{2}$ dari keseluruhan wilayah Kabupaten Konawe Selatan. Menurut peraturan daerah (PERDA) kabupaten konawe selatan nomor 19 tahun 2013 tentang rencana tata ruang wilayah (RTRW) Kabupaten Konawe Selatan sebagaimana yang tertuang dalam Pasal 17 ayat (1), Kawasan hutan lindung, ditetapkan seluas 44.251 (empat puluh empat ribu dua ratus lima puluh satu). Kawasan peruntukan hutan produksi terbatas ditetapkan seluas 3.707 (tiga ribu tujuh ratus tujuh) hektar. Kawasan peruntukan hutan produksi tetap ditetapkan seluas 65.017 (enam puluh lima ribu tujuh belas) hektar.

\section{METODE PENELITIAN \\ Jenis Penelitian}

Jenis penelitian ini berdasarkan rumusan masalah yang ada yaitu penelitian deskriptif kualitatif.

Alat dan Bahan

Tabel 1. Alat yang Digunakan Dalam Penelitian

\begin{tabular}{cll}
\hline No. & \multicolumn{1}{c}{ Alat } & \multicolumn{1}{c}{ Kegunan } \\
\hline 1. & Seperangkat Komputer/PC & Sebagai sarana untuk mengolah semua data yang diperoleh \\
2. & Kamera Digital & Untuk mengambil data gambar di lapangan \\
3. & Alat Tulis & Sebagai sarana untuk menulis wawancara dan data penunjang \\
& & lainnya \\
4. & Software ArcGis 10.2 & Sebagai perangkat yang digunakan untuk mengolah data peta \\
\hline
\end{tabular}

Tabel 2. Bahan Yang Digunakan Dalam Penelitian

\begin{tabular}{cll}
\hline No. & \multicolumn{1}{c}{ Bahan } & \multicolumn{1}{c}{ Kegunaan } \\
1. & Peta Kemiringan Lereng & Sebagai parameter fungsi kawasan hutan \\
2. & Peta jenis Tanah & Sebagai parameter fungsi kawasan hutan \\
3. & Peta Curah Hujan & Sebagai parameter fungsi kawasan hutan \\
4. & Peta Administrasi & Mengetahui sebaran arahan fungsi kawasan hutan tiap \\
& & kecamatan \\
\hline
\end{tabular}




\section{Waktu dan Lokasi Penelitian}

Penelitian ini akan dilaksanakan pada bulan Januari 2019 dengan lokasi Kabupaten Konawe Selatan, Sulawesi Tenggara.

\section{Metode Penelitan}

Metode dalam penelitian ini menggunakan metode overlay dan Scoring, dengan beberapa parameter-parameter didalamnya yaitu, Kemiringan Lereng, Jenis Tanah, dan Curah Hujan.

\section{Teknik Pengumpulan Data}

Jenis data yang digunakan dalam penelitian ini adalah data primer dan data sekunder.

\section{Teknik Analisis Data}

Analisis data yang digunakan dalam penelitian ini adalah overlay dan scoring.

\section{HASIL DAN PEMBAHASAN \\ Hasil Penelitian}

\section{Kelerengan Tanah}

Kemiringan lereng yang terdapat di lokasi penelitian memenuhi semua kategori kelas lereng yang terdiri dari 5 kelas lereng, yaitu kategori lereng datar dengan persentase kemiringan 0-8\% memiliki luas sebesar 134387,84 ha, daerah yang masuk dalam kategori lereng ini diantaranya yaitu Kecamatan Basala, Laonti, dan Mowila. Lereng landai dengan persentase kemiringan 8$15 \%$ memiliki luas sebesar 13582,8 ha, daerah yang masuk dalam kategori lereng ini diantaranya yaitu Kecamatan Kolono, Ranemeeto barat, Moramo Utara, Lainea. Lereng agak curam dengan persentase 15-25\% memiliki luas sebesar 123394,63 ha, daerah yang masuk dalam kategori lereng ini diantaranya yaitu kecamatan Andoolo Barat, Buke, Baito. Lereng Curam dengan persentase $25-40 \%$ memiliki luas sebesar 452,74 ha, daerah yang masuk dalam kategori lereng ini diantaranya yaitu sebagian besar wilayah Tinenggea dan sebagian besar wilayah Lalembuu. Lereng sangat curam dengan persentase $>40 \%$ memiliki luas paling besar yaitu 149550,57 ha, daerah yang masuk dalam kategori lereng diantaranya yaitu Kecamatan Wolasi, Angata, sebagian wilayah Laeya, sebagian wilayah Lelambuu dan Ranomeeto.

Tabel 3. Klasifikasi Kemiringan Lereng di Kabupaten Konawe Selatan

\begin{tabular}{cccc}
\hline No. & Kemiringan Lereng & Skor & Luas (ha) \\
\hline 1. & $0-8 \%$ (Datar) & 20 & 134387,84 \\
2. & $8-15 \%$ (Landai) & 40 & 13582,8 \\
3. & $15-25 \%$ (Agak Curam) & 60 & 123394,63 \\
4. & $25-40 \%$ (Curam) & 80 & 452,74 \\
5. & $>40 \%$ (Sangat Curam) & 100 & 149550,57 \\
& Jumlah & & $\mathbf{4 2 1 3 6 4 , 6 4}$ \\
\hline
\end{tabular}

Sumber: Data olahan ArcGIS, 2019.

\section{Jenis Tanah}

Kabupaten Konawe Selatan mempunyai jenis tanah yang sangat beragam dari jenis tanah tersebut terdapat tiga jenis tanah yang mendominasi yaitu Regosol, jenis tanah ini sangat peka terhadap erosi dan umumnya terdapat pada hutan lindung, tersebar di beberapa kecamatan seperti Kolono, Kolono Timur, Laeya, lalembuu, Tinanggea, Baito, Palangga, Moramo Utara. Jenis tanah yang kedua yaitu Latosol, jenis tanah ini kurang peka terhadap erosi dan umumnya terdapat pada hutan produksi tetap, tersebar di beberapa kecamatan seperti Moramo, Moramo Utara, Buke, Andoolo Barat, Kolono, Palangga Selatan, Tinanggea, Palangga, Wolasi.

Jenis tanah ketiga yaitu Pedzolik, jenis tanah ini peka terhadap erosi dan umumnya terdapat pada hutan produksi terbatas, yang tersebar di beberapa kecamatan Seperti Landono, Mowila, Sabulakoa, Angata, Ranomeeto Barat, Ranomeeto, Lainea. 
Tabel 4. Klasifikasi Jenis Tanah di Kabupaten Konawe Selatan

\begin{tabular}{lcc}
\hline \multicolumn{1}{c}{ Jenis Tanah } & Skor & Luas (ha) \\
\hline Regosol & 75 & 15537,04 \\
Regosol, latosol & 75 & 90901,46 \\
Regosol, Latosol, Gray brown podsolic & 75 & 8518,43 \\
Regosol, Mediteran & 75 & 48103,16 \\
Gray brown podsolic, latosol & 60 & 507584,03 \\
Podsolik coklat, alluvial & 60 & 1335,21 \\
Red Yellow Podsolic & 60 & 5526,46 \\
Latosol & 30 & 7107,24 \\
Latosol, Regosol & 30 & 144765,03 \\
Latosol, Regosol, Latosol merah kuning & 30 & 4539,12 \\
Latosol, Regosol, Low humic gley & 30 & 18208,18 \\
Acid sulfat soils, alluvial & 15 & 18361,06 \\
Acid sulfat soils, alluvial, podsolik coklat & 15 & 7438,09 \\
Low humic gley, acid sulfat soils & 15 & 32706,81 \\
Low humic gley, alluvial & 15 & 366,36 \\
Low humic gley, alluvial, acid sulfat soils & 15 & 988,25 \\
Rendzina & 75 & 2790,76 \\
Rendzina, Regosol & 75 & 7850,95 \\
\hline
\end{tabular}

Sumber: Data olahan ArcGIS, 2019.

\section{Curah Hujan}

Setelah melewati tahap skoring dapat di lihat pada tabel di atas curah hujan perkecamatan yang berada di kabupaten Konawe Selatan, dari 25 kecamatan ada dua kecamatan yang di jadikan sampel dalam penelitian ini yaitu kecamatan Kolono dan kecamatan Moramo, kedua kecamatan ini mempunyai curah hujan harian yang rendah sampai kategori sedang yaitu 3,24 sampai $6,33 \mathrm{~mm} /$ hari, hal ini di buktikan dengan kondisi daerah yang cikup air sehingga dap memenuhi kebutuhan pengairan sehari-hari, pertanian maupun perkebunan. Sebagaimana daerah-daerah lain di Indonesia, Kabupaten
Konawe Selatan hanya mengenal dua musim yakni musim kemarau dan musim hujan. Keadaan musim sangat dipengaruhi oleh arus angin yang bertiup di atas wilayahnya. Kecamatan yang ada di Kabupaten Konawe Selatan mempunyai intensitas curah hujan dengan rata-rat kategori rendah dimana curah hujan harian di Kabupaten Konawe Selatan hanya berkisar 2,23 mm/hari - $6,33 \mathrm{~mm} / \mathrm{hari}$. Data curah di peroleh dari Peta Geo. spasial dalam bentuk peta (format Shp). Adapun curah hujan di Kabupaten Konawe Selatan adalah sebagai berikut: 
Tabel 5. Klasifikasi Curah Hujan di Kabupaten Konawe Selatan

\begin{tabular}{cccccc}
\hline No. & $\begin{array}{c}\text { Curah Hujan } \\
\text { Tahunan }(\mathbf{m m})\end{array}$ & $\begin{array}{c}\text { Curah Hujan } \\
\text { Harian }(\mathbf{m m})\end{array}$ & Skor & Luas (ha) & Persentase \\
\hline 1. & 812,78 & 2,23 & 10 & 20453,12 & $5 \%$ \\
2. & 1183,31 & 3,24 & 10 & 4793,16 & $1 \%$ \\
3. & 1469,56 & 4,03 & 10 & 26322,38 & $6 \%$ \\
4. & 1502,03 & 4,12 & 10 & 75384,66 & $18 \%$ \\
5. & 1716,93 & 4,7 & 10 & 56196,21 & $13 \%$ \\
6. & 1730,9 & 4,74 & 10 & 42271,22 & $10 \%$ \\
7. & 1956,74 & 5,36 & 10 & 55657,64 & $13 \%$ \\
8. & 2008,62 & 5,5 & 10 & 326,38 & $0 \%$ \\
9. & 2086,54 & 5,72 & 10 & 424,46 & $0 \%$ \\
10. & 2093,15 & 5,73 & 10 & 31240,22 & $8 \%$ \\
11. & 2310,02 & 6,33 & 10 & 108297,19 & $26 \%$ \\
\hline \multicolumn{5}{c}{ Jumlah } &
\end{tabular}

Sumber: Data olahan ArcGIS, 2019.

\section{Peta Arahan Fungsi Kawasan Hutan}

Berdasarkan hasil dari 3 (tiga) parameter arahan fungsi kawasan hutan yang di jadikan sebagai acuan hasil dari overlay untuk menetukan tingkat arahan fungsi kawasan dalam menganalisa data spasial. Dari overlay peta dari 3 (tiga) parameter di atas, sehingga dapat diakumulasikan dengan cara menjumlahkan skor ketiga parameter tersebut untuk memperoleh skor total arahan fungsi kawasan hutan.

$\mathbf{A F K}=\mathbf{K L}+\mathbf{J T}+\mathbf{C H}$
Keterangan:

AFK= Skor Total Arahan Fungsi Kawasan

$\mathrm{KL}=$ Skor Kemiringan lereng

$\mathrm{JT}=$ Skor Jenis Tanah

$\mathrm{CH}=\quad$ Skor Curah Hujan

Dari hasil penjumlahan ketiga skor parameter tersebut dapat menentukan ketiga kategori arahan fungsi kawasan hutan yang telah di overlay, untuk mengetahui hasil overlay peta parameter dalam menganalisa data spasial, adapun data tersebut dapat dilihat pada tabel (5.10) berikut:

Tabel 6. Kriteria Penetapan Fungsi Kawasan Hutan.

\begin{tabular}{clc}
\hline No. & Fungsi Kawasan & Total nilai skor \\
\hline 1. & Kawasan Hutan Lindung & $\geq 175$ \\
2. & Kawasan Hutan Produksi Terbatas & $125-174$ \\
3. & Kawasan Hutan Produksi Tetap & $<124$ \\
\hline
\end{tabular}

Sumber: Data olahan ArcGIS, 2019.

Tabel 7. Klasifikasi Fungsi Kawasan Hutan di Kabupaten Konawe Selatan

\begin{tabular}{clcc}
\hline No. & $\begin{array}{c}\text { Klasifikasi Arahan Fungsi } \\
\text { Kawasan }\end{array}$ & $\begin{array}{c}\text { Luasan/Hektare } \\
(\text { Ha) }\end{array}$ & Persentase \\
\hline 1. & Hutan lindung & 109495,28 & $24 \%$ \\
2. & Hutan Produksi Terbatas & 51363,48 & $13 \%$ \\
3. & Hutan Produksi Tetap & 260505,86 & $63 \%$ \\
\hline & Jumlah & $\mathbf{4 2 1 3 6 4 , 6 4}$ & $\mathbf{1 0 0 \%}$ \\
\hline
\end{tabular}

Sumber: Data olahan ArcGIS, 2019. 




Gambar 1. Peta Persebaran Arahan Fungsi Kawasan Hutan Konawe Selatan

(Hasil Olahan ArcGIS, 2019)

Luasan arahan fungsi kawasan hutan di Kabupaten Konawe Selatan di bagi menjadi 3 fungsi kawasan yaitu Hutan Lindung, Hutan Produksi Tetap dan Hutan Produksi Terbatas. Wilayah Kabupaten Konawe Selatan terdapat tiga jenis arahan hutan yang mempunyai luas yang berbeda-beda, diantaranya hutan lindung seluas 109495,28 ha, hutan produksi tetap seluas 260505,86 ha, hutan produksi terbatas 51363,48 ha. Dari ketiga luasan arahan fungsi kawasan hutan tersebut hutan produksi tetap mempunyai persentase terbesar diikuti hutan lindung lalu selanjutnya hutan produksi terbatas.

Dari tabel di bawah dapat dilihat bahwa lokasi Kabupaten Konawe Selatan dengan Hutan Lindung Terbesar terdapat pada kecamatan Kolono dengan luas hutan 19314,18 Ha, Wolasi dengan luas hutan 12724,56 Ha, selanjutnya kecamatan Moramo seluas 12493,89 Ha. Tiga kecamatan tersebut mempunyai luasan hutan lindung terbesar dibandingkan dengan 22 kecamatan lainnya, selain itu terdapat 6 kecamatan yang tidak mempunyai hutan lindung di antaranya yaitu kecamatan Sabulakoa, Andoolo, Basala, Benua, Andoolo Barat, dan Palangga Selatan.

Hutan produksi tetap dengan luasan terbesar terdapat di Kecamatan Angata dengan luas 15226,14 Ha dan Kecamatan Buke dengan luas hutan 14321,39 ha . Kategori dengan luas hutan terendah yaitu terdapat pada kecamatan Moramo Utara dimana hutan produksi tetap hanya seluas 3800,11 Ha. Untuk kategori Hutan produksi terbatas luasan terbesar terdapat di kecamatan Kolono dengan luas hutan 10617,32 Ha, diikuti oleh Kecamatan Angata dengan luas h utan 9724,61 Ha dan kecamatan Lainea dengan luas hutan 6109,85 Ha. Terdapat beberapa kematan yang tidak memiliki hutan produksi terbatar diantaranya yaitu kecamatan Andoolo Barat, Kolono Timur, Buke dan Baito. Di bawah ini merupakan pembagian arahan fungsi kawasan hutan yang dibagi perkecamatan. 
Tabel 7. Sebaran Fungsi Kawasan Hutan Perkecamatan

\begin{tabular}{|c|c|c|c|c|}
\hline \multirow[b]{2}{*}{ No. } & \multirow[b]{2}{*}{ Kecamatan } & \multicolumn{3}{|c|}{ LUAS (Hektare/Ha) } \\
\hline & & $\begin{array}{c}\text { Hutan } \\
\text { Lindung }\end{array}$ & $\begin{array}{c}\text { Hutan Produksi } \\
\text { Tetap }\end{array}$ & Hutan Produksi Terbatas \\
\hline 1. & Sabulakoa & - & 5783,49 & 1454,53 \\
\hline 2. & Tinanggea & 1569,57 & 27417,1 & 1669,67 \\
\hline 3. & Andoolo & - & 10453,68 & 94,67 \\
\hline 4. & Baito & 9007,65 & 10227,71 & - \\
\hline 5. & Mowila & 1322,55 & 7169,1 & 3049,32 \\
\hline 6. & Buke & 889,92 & 14321,39 & - \\
\hline 7. & Lainea & 9965,15 & 8013,47 & 6109,85 \\
\hline 8. & Palangga & 2129,97 & 10254,64 & 2807,92 \\
\hline 9. & Angata & 1240,69 & 15226,14 & 9724,61 \\
\hline 10. & Lalembuu & 4904,72 & 15385,1 & 2054,03 \\
\hline 11. & Basala & - & 10151,47 & 2053,03 \\
\hline 12. & Benua & - & 10235,88 & 252,57 \\
\hline 13. & Moramo Utara & 9488,25 & 3800,11 & 333,47 \\
\hline 14. & Laonti & 1750,83 & 3927,33 & 1828,43 \\
\hline 15. & Moramo & 12493,89 & 7889,97 & 3723,9 \\
\hline 16. & Wolasi & 12724,56 & 3773,51 & 642,09 \\
\hline 17. & Landono & 4243,75 & 5729,43 & 1157,71 \\
\hline 18. & Konda & 5489,83 & 6975,91 & 21,86 \\
\hline 19. & Kolono & 19314,18 & 7277,15 & 10617,32 \\
\hline 20. & Kolono Timur & 4884,08 & 6036,75 & - \\
\hline 21. & Ranomeeto Barat & 165,95 & 5752,1 & 235,48 \\
\hline 22. & Ranomeeto & 1572,25 & 5111,73 & 2154,9 \\
\hline 23. & Andoolo Barat & - & 6356,4 & - \\
\hline 24. & Laeya & 2574,09 & 15312,48 & 1128,3 \\
\hline 25. & Palangga Selatan & - & 7923,81 & 2303,83 \\
\hline & Jumlah & 109495,28 & 260505,86 & 51363,48 \\
\hline
\end{tabular}

Sumber: Data olahan ArcGIS, 2019.

Setelah melewati tahap skoring dan overlay dapat dilihat sebaran arahan fungsi kawasan hutan yang berada di kabupaten Konawe Selatan, dari tabel di atas dari 25 kecamatan di ambil dua sampel kecamatan yaitu kecamatan Kolono dan Kecamatan Moramo untuk di uji dengan keadaan sebenarnya. Kecamatan Kolono dan kecamatan Moramo mempunyai 3 jenis fungsi kawasan hutan dengan luasan yang berbeda pula, di antaranya yaitu kawasan hutan produksi tetap yaitu kawasan yang dapat di eksploitasi dan di di peruntukkan untuk masyarakat, dengan luas masing-masing kecamatan Kolono 7277,15 ha dan kecamatan Moramo 7889,97 ha, hal ini juga dapat di buktikan pada saat peneliti melakukan validasi sebagian besar wilayah kecamatan Kolono dan kecamatan Moramo merupakan daerah

perkebunan di antaranya perkebunan jambu biji, perkebunan kelapa, perkebunan jati, pisang dan sebagian besar lagi merupakan persawahan.

Kawasan hutan produksi terbatas merupakan kawasan yang dapat di lakukan eksploitasi tetapi dengan cara tebang pilih, di kecamatan Kolono seluas 10617,32 ha, dan kecamatan moramo seluas 3723,9 ha, hal ini dapat di buktikan dengan sebagian besar daerah pada kecamatan kolono dan sebagian kecamatan Moramo yang merupakan wilayah berbukit dan kemiringan lereng yang agak curam yang cenderung susah untuk dilakukan eksploitasi.

Kawasan hutan lindung merupakan kawasan hutan yang karena keadaan sifat alamnya diperuntukkan guna pengaturan tata air, pencegahan bahaya banjir dan erosi, serta pemeliharaan kesuburan tanah, di kecamatan 
Kolono seluas 19314,18 ha dan kecamatan Moramo seluas 12493,89 ha, hal ini dapat di buktikan pada saat peneliti melakukan validasi lapangan, pada kecamatan Kolono sebagian besar wilayahnya merupakan kawasan lindung mengingat sebagian besar wilayahnya merupakan rawan bencana dan sangat peka terhadap erosi, hal ini juga di dukung oleh wilayahnya yang sebagian besar berbukit dan pegunungan, dengan vegetasi yang cukup subur, selain itu pohon yang tumbuh di sebagian areanya merupakan pohon dengan usia yang tua dan besar seperti pohon toho yang mempunyai struktur yang besar dan tinggi.

Kecamatan Moramo sebagian besar wilayahnya juga merupakan kawasan hutan lindung hal ini dapat di buktikan peneliti pada saat melakukan validasi di area lindung yaitu di area suaka alam air terjun sember sari atau sering di sebut dengan tanjung peropa, area ini memenuhi syarat untuk di tetapkan sebagai kawasan lindung karena pada kawasan ini terdapat satwa yang dilindungi yaitu monyet hitam, pohong yang tumbuh di area ini juga merupakan pohon yang mempunyai umur ratusan tahun dan sering terdapat di hutan hujan tropis seperti pohon gito-gito, pohon rawu, dan pohon kase yang mempunyai struktur tinggi dan besar, selain itu kawasan ini juga menjadi area perlindungan mata air yang di gunakan masyarakat sekitar, kawasan ini juga telah di resmikan pada tahun 2013 oleh dinas kehutanan provinsi Sulawesi Tenggara sebagai kawasan komplek Hutan Papalia dan di jadikan area wisata oleh Dinas Kehutanan.

\section{Fungsi Kawasan Hutan Menurut RTRW Konawe Selatan}

Tabel 8. Sebaran Fungsi Kawasan Hutan Yang Berada di Kabupaten Konawe Selatan

\begin{tabular}{ccc}
\hline No. & Fungsi Kawasan Hutan & Luas (ha) \\
\hline 1. & AIR & 912,54 \\
2. & APL & 237722,04 \\
3. & HL & 43089,34 \\
4. & HP & 64881,78 \\
5. & HPT & 3706,79 \\
6. & HSA & 71052,14 \\
\hline & Jumlah & $\mathbf{4 2 1 3 6 4 , 6 4}$ \\
\hline
\end{tabular}

Sumber: Data olahan ArcGIS, 2019.

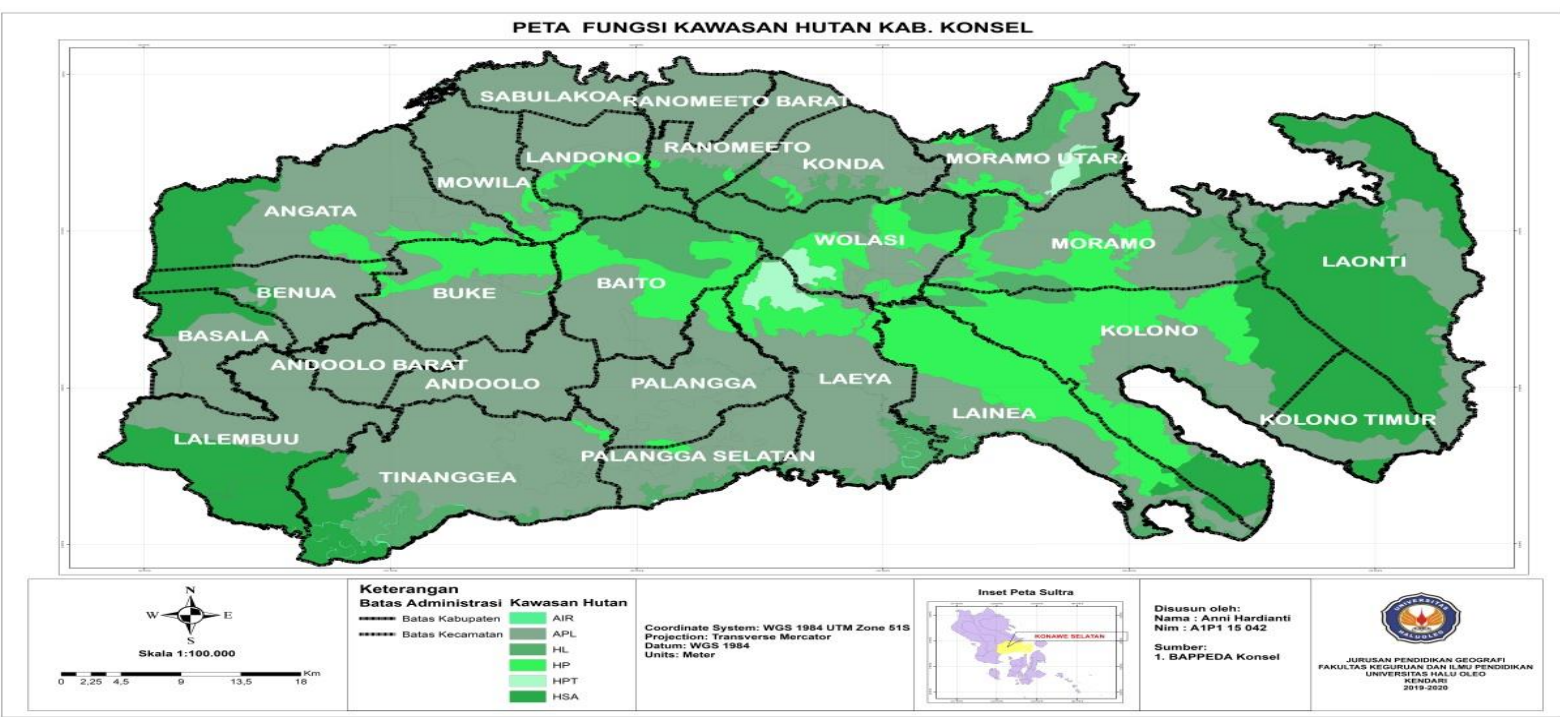

Gambar 2. Peta Fungsi Kawasan Hutan Konsel (BAPPEDA Kabupeten Konawe Selatan, 2019).

Dari tabel di atas dapat dilihat fungsi kawasan hutan menurut RTRW di Kabupaten Konawe Selatanbeserta luas dari tiap fungsi kawasan hutan. Luas dari area tubuh air sebesar 912,54, luas dari area penggunaan lain sebesar 237722,04, luas dari hutan lindung sebesar 
43089,34, luas dari hutan produksi tetap sebesar 64881,78 , luas dari hutan produksi terbatas 3706,79 , luas dari hutan suaka alam sebesar 71052,14 .

Berdasarkan data diatas, terdapat 4 kategori fungsi kawasan hutan menurut RTRW Kabupaten Konawe Selatan nomor 19 tahun 2013, yaitu hutan lindung, hutan produksi, hutan produksi terbatas dan hutan suaka alam, area lain yang merupakan tubuh air dan area pemanfaatan lain. Area pemanfaatan hutan adalah seluas 182730,05 atau $43,36 \%$ dari seluruh luas wilayah administrasi. Dari tabel di atas dapat dilihat fungsi kawasan hutan menurut RTRW di Kabupaten Konawe Selatanbeserta luas dari tiap fungsi kawasan hutan. Luas dari area tubuh air sebesar 912,54, luas dari area penggunaan lain sebesar 237722,04, luas dari hutan lindung sebesar 43089,34, luas dari hutan produksi tetap sebesar 64881,78, luas dari hutan produksi terbatas 3706,79 , luas dari hutan suaka alam sebesar 71052,14.

Berdasarkan data diatas, terdapat 4 kategori fungsi kawasan hutan menurut RTRW Kabupaten Konawe Selatan nomor 19 tahun 2013, yaitu hutan lindung, hutan produksi, hutan produksi terbatas dan hutan suaka alam, area lain yang merupakan tubuh air dan area pemanfaatan lain. Area pemanfaatan hutan adalah seluas 182730,05 atau $43,36 \%$ dari seluruh luas wilayah administrasi.

Tabel 9. Pemanfaatan Lahan Yang Berada di Kabupaten Konawe Selatan

\begin{tabular}{clcc}
\hline No & \multicolumn{1}{c}{ Pemanfaatan Lahan } & Luas (ha) & Persentase \\
\hline 1. & Hutan & 182730,05 & $43,36 \%$ \\
2. & Non hutan & 238634,59 & $56,64 \%$ \\
\hline & Jumlah & $\mathbf{4 2 1 3 6 4 , 6 4}$ & $\mathbf{1 0 0 \%}$ \\
\hline
\end{tabular}

Sumber: Data olahan ArcGIS, 2019.

\section{Perbandingan Arahan Fungsi Kawasan Hutan Dan Hutan Menurut RTRW Kab. Konsel}

Tabel 10. Perbandingan Arahan Fungsi Kawasan Hutan Dan Hutan Menurut RTRW Kab. Konsel

\begin{tabular}{|c|c|c|c|c|}
\hline No. & $\begin{array}{l}\text { Arahan Fungsi } \\
\text { Kawasan Hutan }\end{array}$ & $\begin{array}{l}\text { Kawasan Hutan } \\
\text { RTRW }\end{array}$ & Keterangan & $\begin{array}{l}\text { Luas } \\
\text { (ha) }\end{array}$ \\
\hline 1. & Hutan Lindung & Hutan Lindung & Sesuai & 27430,05 \\
\hline 2. & Hutan Lindung & Hutan Suaka Alam & Sesuai & 10485,50 \\
\hline 3. & Hutan Lindung & Hutan Produksi & Tidak sesuai & 41643,18 \\
\hline 4. & Hutan Lindung & $\begin{array}{l}\text { Hutan Produksi } \\
\text { Terbatas }\end{array}$ & Tidak sesuai & 3292,9 \\
\hline 5. & $\begin{array}{l}\text { Hutan Produksi } \\
\text { Terbatas }\end{array}$ & Hutan Lindung & Sesuai & 4495,62 \\
\hline 6. & $\begin{array}{l}\text { Hutan Produksi } \\
\text { Terbatas }\end{array}$ & Hutan Suaka Alam & Sesuai & 5075,98 \\
\hline 7. & $\begin{array}{l}\text { Hutan Produksi } \\
\text { Terbatas }\end{array}$ & Hutan Produksi & Tidak Sesuai & 8502,23 \\
\hline 8. & Hutan Produksi Tetap & Hutan Lindung & Sesuai & 11163,67 \\
\hline 9. & Hutan Produksi Tetap & Hutan Suaka Alam & Sesuai & 54860,66 \\
\hline 10. & Hutan Produksi Tetap & Hutan Produksi & Sesuai & 14736,37 \\
\hline 11. & Hutan Produksi Tetap & $\begin{array}{l}\text { Hutan Produksi } \\
\text { Terbatas }\end{array}$ & Tidak Sesuai & 413,89 \\
\hline \multicolumn{4}{|c|}{ Jumlah } & $\mathbf{1 8 2 7 3 0 , 0 5}$ \\
\hline \multicolumn{3}{|c|}{ Menurut tabel di atas, perbandingan antara } & \multicolumn{2}{|c|}{$\begin{array}{l}\text { dengan } \\
\text { analisis arahan fungsi kawasan hutan di Kabupate } \\
n \text { KonaweSelatan. Perbandingan dilihatdari segi } 1 \\
\text { uasan hutan dengan jenis fungsi kawasan hutanny } \\
\text { a. SK Menteri pertanian No.837/KPTS/UM/11/1 } \\
980 \text { dan No.683/KPTS/UM/8/1981 serta KEPPR } \\
\text { ES No.32/1990 menunjukkan bahwa hasil output } \\
\text { peta memiliki tiga arahan fungsi kawasan hutan }\end{array}$} \\
\hline
\end{tabular}


yaitu hutan produksi, hutan produksi terbatas, dan hutan lindung (gambar 5.4) sedangkan menurut peta kawasan kehutanan dari RTRW Kabupaten Konawe Selatan menunjukkan bahwa terdapat enam fungsi kawasan hutan yaitu hutan produksi, hutan produksi terbatas, huta lindung, kawasan perlindungan air, area pemanfaatan lain, dan hutan suaka alam (Gambar 5).

Menurut peraturan pemerintah No.104 Tahun 2015 tentang fungsi kawasan hutan, hutan suaka alam yang fungsinya sama dengan hutan lindung. Hutan produksi adalah kawasan hutan yang dapat dieksploitasi secara menyeluruh dengan menggunakan teknik tebang habis maupun tebang pilih. Sedangkan untuk hutan suaka alam fungsinya sama dengan kawasan hutan lindung yaitu kawasan hutan yang dikelola dengan tujuan untuk melindungi kekayaan keanekaragaman hayati atau keindahan alam yang ada di dalamnya sehingga secara fungsinya dijadikan sebagai kawasan lindung, untuk area perlindungan air yaitu kawasan yang di jadikan sebagai area perlindungan mata air yang sama fungsinya dengan kawasan hutan lindung dengan tujuan melindungi kawasan mata air sehingga dijadikan sebagai kawasan lindung.

Berdasarkan data tabel tersebut untuk arahan hutan lindung yang ditempati oleh hutan lindung adalah seluas 27430,05 ha. Kemudian arahan hutan lindung yang ditempati oleh hutan suaka alam memiliki luas sebesar 10485,50 ha dengan. Selanjutnya arahan hutan lindung yang ditempati oleh hutan produksi memiliki luas sebesar 41643,18 ha dan arahan hutan lindung yang ditempati oleh hutan produksi terbatas memiliki luas 3292,9 ha, serta untuk arahan hutan produksi terbatas yang ditempati oleh hutan lindung luasnya sebesar 4495,62 ha dengan.

Arahan hutan produksi terbatas yang ditempati oleh hutan suaka alam memiliki luas 5075,98 ha. Kemudian arahan hutan produksi terbatas yang ditempati oleh hutan produksi luasnya sebesar 8502,23 ha. Selanjutnya arahan hutan produksi tetap yang ditempati oleh hutan lindung memiliki luas sebesar 11163,67 ha, serta arahan hutan produksi tetap yang ditempati oleh hutan suaka alam memiliki luas sebesar 54860,66 ha. Arahan hutan produksi tetap yang ditempati oleh hutan produksi seluas 14736,37 ha. Kemudian arahan hutan produk si tetap yang ditempati oleh hutan produksi terbatas memiliki luas 413,89 ha.

Penentuan peruntukkan arahan fungsi kawasan hutan dari SK Menteri Pertanian adalah mencari potensi-potensi kawasan yang bisa diperuntukkan untuk arahan hutan, namun tidak semua kawasan dapat diperuntukkan sebagai kawasan hutan.

\section{Pembahasan}

Berdasarkan hasil penglolahan data parameter-parameter arahan fungsi kawasan hutan melalui aplikasi SIG, maka di peroleh 3 fungsi kawasan hutan di Kabupaten Konawe Selatan. Kabupaten Konawe Selatan memiliki luas kawasan hutan sebesar $190.563 \mathrm{Km}^{2}$ (Data statistik Kehutanan), kawasan hutan lindung seluas 109495,28 ha, hutan produksi tetap seluas 260505,86 ha, dan hutan produksi terbatas 51363,48 ha.

Menurut UU No.41 Tahun 1999 tentang kawasan hutan adalah wilayah yang ditunjuk atau ditetapkan oleh pemerintahan untuk dipertahankan keberadaanya sebagai hutan tetap dengan fungsi hutan produksi, fungsi hutan produksi terbatas dan fungsi hutan lindung. Setiap fungsi kawasan hutan tersebut dapat ditentukan jika terlebih dahulu dapat diketahui arahannya. Arahan fungsi kawasan hutan berkaitan dengan indikator parameter yang digunakan dimana tiap parameter mempunyai scoring penentuan arahan fungsi kawasan hutan yaitu skor dengan jumlah $\leq 124$ maka dicadangkan sebagai hutan produksi, skor dengan jumlah 125-175 maka dicadangkan sebagai hutan produksi terbatas dan skor dengan jumlah maka dicadangkan sebagai hutan lindung $\geq 175$.

Ada kriteria-kriteria tertentu suatu kawasan ditunjuk sebagai fungsi kawasan hutan. Jika suatu kawasan yang bersangkutan maupun kawasan yang berada disekitarnya terdapat penyimpanan cadangan air atau dapat mencegah banjir dan erosi maka kawasan tersebut perlu dibina dan dipertahankan sebagai kawasan lindung. Kedua kriteria dari kawasan penyangga jika suatu kawasan yang kriteria keadaan fisik satuan lahannya memungkinkan untuk dilakukan budidaya yang bersifat pertanian serta tidak merugikan segi-segi ekologi apabila dikembangkan sebagai kawasan penyangga dan ketiga kriteria kawasan budidaya jika suatu kawasan memiliki skor dengan jumlah $\leq 124$ dan pemanfaatannya bisa dimanfaatkan diberbagai penggunaan lahan misalnya seperti permukiman, perkebunan, ataupun pertanian. Pihak KPH (Kesatuan Pengelolaan Hutan) Kabupaten Konawe Selatan mengambil tindakan untuk meminimalisir terjadinya pemanfaatan kawasan hutan diluar fungsinya yaitu dengan cara 
masyarakat diizinkan untuk berkebun didalam kawasan lindung tapi tidak boleh untuk membangun dan diadakannya kegiatan perhutanan sosial. Kegiatan perhutanan sosial merujuk pada SK No.P83 Tahun 2016 adalah sistem pengelolaan hutan lestari yang dilaksanakan dalam kawasan hutan yang dilaksanakan oleh masyarakat setempat untuk meningkatkan kesejahteraan, keseimbangan lingkungan dan dinamika sosial budaya dalam bentuk hutan desa, hutan kemasyarakatan, dan kemitraan kehutanan. Kegiatan ini mempunyai tujuan untuk menyejahterakan masyarakat sekitar hutan melalui mekanisme pemberdayaan dan tetap berpedoman pada aspek kelestarian hutan sehingga dengan adanya kegiatan perhutanan sosial masyarakat diharapkan mampu untuk memanfaatkan hutan dengan baik sesuai fungsi masing-masing.

\section{PENUTUP}

\section{Kesimpulan}

Persebaran arahan fungsi kawasan hutan di Kabupaten Konawe Selatan terdiri atas tiga yaitu kawasan hutan lindung, kawasan hutan produksi tetap dan kawasan hutan produksi terbatas. Kawasan hutan lindung di Kabupaten Konawe Selatan terletak di beberapa kecamatan seperti Kecamatan Wolasi, Moramo utara, Moramo, Konda, Laeya, Kolono, Kolono timur, Baito, Buke, Landono, Ranomeeto, Mowila, palangga dan tinanggea yang mempunyai luas sebesar 109495,28 ha, Kabupaten konawe selatan masing-masing mempunyai kawasan hutan produksi tetap di setiap kecamatannya seluas 260505,86 ha. Kawasan hutan produksi terbatas di Kabupaten Konawe Selatan, terdapat beberapa kecamatan yang tidak mempunyai hutan produksi terbatas seperti Kolono timur, Andoolo barat, Buke dan Baito seluas 51363,48 ha.

\section{Saran}

Berdasarkan hasil analisis dari penelitian ini, maka dapat diberikan beberapa saran untuk penelitian selanjutnya agar menjadi lebih baik, antara lain:

1. Hendaknya mengambil sampel sebanyak mungkin pada saat validasi agar tingkat keakuratan semakin valid.
2. Memperbanyak literatur terlebih dahulu sebelum melakukan penelitian agar mendapatkan hasil yang lebih baik daripada penelitian sebelumnya.

3. Perizinan dalam permintaan data sebaiknya dibuat jauh-jauh hari sebelum penelitian dilakukan karena membutuhkan waktu yang cukup lama.

4. Memberikan copy laporan hasil penelitian kepada instansi terkait sebagai bukti bahwa penelitian benar-benar dilakukan dan data yang didapat benar-benar digunakan sebagaimana mestinya.

\section{DAFTAR PUSTAKA}

Badan Pusat Statistik. Tahun 2013. Kabupaten Konawe Selatan Dalam Angka Tahun 2013.

https://Badanpusatstatistiktahun2013.com/

(Diakses 12 Desember 2018)

Badan Pusat Statistik. Tahun 2018, Kabupaten Konawe Selatan Dalam Angka Tahun 2018.

https://Badanpusatstatistiktahunkonsel201 8.com/ (Diakses 12 Desember 2018)

Eddy. 2009. Sistem Informasi Geografi KonsepKonsep Dasar. Bandung: Informatika Bandung.

Prahasta. 2005. Sistem Informasi Geografis: Konsep-konsep Dasar Informasi Geografis. Bandung: Informatika Bandung.

DEPHUTBUN. 1999. Undang-Undang No. 41 Tahun 1999

Soekidjo. 1994 Pengembangan Potensi Wilayah. Bandung: Gramedia.

Statistik Kehutanan Provinsi Sulawesi Tenggara. Luas kawasan Hutan berdasarkan SK MENHUTBUN No.454/ kpts-II/1999 Tanggal 17 Juni 2011.

DEPHUTBUN. Tentang Kehutanan. Jakarta Undang-undang No. 5 Tanun 1967 Pasal 1 Tentang Pengertian Hutan Secara Konseptual Yuridis.

Pengelola Jurnal Penelitian Pendidikan Geografi La Ode Amaluddin

Gedung FKIP Lt. 2 Universitas Halu Oleo. Kampus Bumi Tridharma Anduonohu Kendari93232

Email: amaluddin.75@gmail.com 